\title{
Book Review: When the World Collapses
}

\section{Kevin Aho: Contexts of Suffering. A Heideggerian Approach to Psychopathology. Rowman and Littlefield: London, 2019, 119 pp. + References and Index. Ppb. \$44.95, Hdb. \$135.00.}

\author{
Steven Taubeneck ${ }^{1}$ \\ Published online: 5 August 2020 \\ (c) Springer Nature B.V. 2020
}

Over just a few months it could be said that our world has collapsed. Haunted by contagion, many have lost a sense of their future possibilities, if not of themselves. Kevin Aho's book, published in late 2019, sheds light on problems suffered especially during the coronavirus pandemic of 2020. On the basis of a well-informed reading of many of Martin Heidegger's texts, from the early (1924) Concept of Time to the late (1959-1971) Zollikon Seminars, Aho derives an approach that can be applied to the growing psychopathologies of our time. Along the way, he brings together resources from phenomenology, existentialism and hermeneutics to argue for a thorough rethinking of biomedical psychiatry in the U.S. His book is a powerful example of transdisciplinary work at its most effective, particularly when applied to urgent problems in contemporary life.

The "Introduction," on "Heidegger and Psychiatry," sets the stage for the book by establishing a framework for bringing philosophy and psychiatry together. Aho begins by proclaiming that "Modern psychiatry is in crisis" (p. xi). To be sure, there have been significant pharmaceutical breakthroughs in the treatment of mental illness. But at the same time many Americans seem more dissatisfied than ever. As a result, according to Aho, psychiatry itself has been called into question. Questions mount up, especially regarding the Diagnostic and Statistical Manual of Mental Disorders (DSM), which now considers over 365 disorders. For Aho, the main problem with the field is its "biologically based approach that focuses almost exclusively on the use of medications to affect changes in brain chemistry" (p. xi). By contrast, Aho argues for a Heideggerian approach to psychotherapy that brings "the whole person and their irreducible social contexts back into the therapeutic encounter" (p. xii). In order to better treat someone as a whole person, the therapist should put aside the detached, biological emphasis of common practice and value the patient's first-person perspective.

Steven Taubeneck

taubenst@mail.ubc.ca

1 University of British Columbia, Vancouver, BC, Canada 
At first it may seem strange to bring Heidegger into the context of mental health. Wasn't it Heidegger, after all, who wrote against humanism in his "Letter on Humanism?" And didn't he, too, become a member of the Nazi Party, serve as the Rector of Freiburg University for a time under the Nazis, and compose the infamous Black Notebooks, which have recently exposed his polemical anti-Semitism? Aho admits these "darker" issues but follows Charles Guignon, his teacher and one of Heidegger's more original interpreters, by finding "something less sinister afoot" (p. 116). As Heidegger wrote in his "Letter": "It ought to be somewhat clearer now that opposition to 'humanism' in no way implies a defense of the inhuman but rather opens other vistas" (1993: p. 250). In Contexts, Aho builds on his expertise regarding Heidegger's works to open "other vistas" for understanding not only Heidegger but also philosophy and psychiatry.

With this book Aho joins a growing number of writers in applying methods of phenomenology to challenge the biochemical emphasis in contemporary psychiatry. Perhaps the most comprehensive recent contribution to this field is The Oxford Handbook of Phenomenological Psychopathology (2019), with articles that include Aho's own, on "Affectivity and Its Disorders." Particularly in light of the overlapping troubles of 2020, including the coronavirus pandemic, widespread economic dislocation and the increasing willingness to confront racist policies and practices, it seems more important than ever to contextualize each person's situation in order to understand their mental condition. If we adopt a more phenomenological approach to mental illness, Aho argues, we will discover more of "what it feels like from the perspective of the patient" (p. xv), upon "the collapse of our world and the paralyzing dissolution of the self" (p. 55).

In the first part of the book, on "Phenomenological Psychopathology," Aho challenges "the rise of medicalization" in psychiatry, which tends to combine "cognitive neuroscience, brain imaging, pharmacology, and molecular genetics" in order to emphasize biochemical imbalances over social or historical factors (p. 3). For him, the claims of biopsychiatry are too one-sided. Instead he recommends Heidegger's kind of phenomenology, which "begins with first-person descriptions of our own ordinary existence" (p. 12). On Aho's reading of Heidegger, "our everyday ability to interpret and make sense of things is structured by 'care' (Sorge)" (p. 12). If it is through care that we shape our self-understanding, then it becomes important for the therapist to uncover how the patient cares about what they care about and why.

Aho identifies six elements comprising Heidegger's account of care: moods, embodiment, spatiality, relationality, temporality, and understanding. The emphasis on "moods" is among Heidegger's most important contributions. For him, "Mood is above all a way of being attuned, and letting ourselves be attuned, in this or that way" (Heidegger 1979: p. 99; Aho, p. 13). With his emphasis on moods, Heidegger transforms the view of what constitutes humanness. Instead of being first and foremost rational or spiritual, humans are primarily "attuned" to what he calls their "situatedness" (p. 13). We are enmeshed in the world, and benefit of Heidegger's approach is that he describes more precisely the kinds of attunement we experience. The overview Aho provides in Contexts provides a clear, useful basis for interpreting mental health. One of his strengths is the ability to provide accessible accounts of Heidegger's terms and to link them succinctly. 
The other elements in Heidegger's care structure differentiate our existential engagements with the world. In terms of our embodiment he argued that: "We do not 'have' a body; rather, we 'are' bodily" (Heidegger 1979: p. 99; Aho, p. 15). This means, as Aho puts it: "my body is... already bound up and entwined in a practical life-world" (p. 15). What happens in phases of mental illness is that the "seamless" role of the body is disrupted, and it becomes "an obstacle or burden" (p. 15). Along with the disruptions of embodiment our awareness of space, relationships, time and understanding become distorted. In terms of spatiality "it becomes difficult to handle things, to negotiate with others in social situations" (p. 17). If our existence is relational and intersubjective, when our mental health breaks down we struggle with the personal and social expectations we associate with normalcy. The relational ontology out of which we live becomes fractured, leading potentially to shame, guilt, and behavior that might lead us into social isolation. Our sense of time can also become distorted. Aho finds more support for this point from the work of Thomas Fuchs, who wrote of "bodily disunity" in episodes of mental illness (p. 18). Yet Heidegger's analysis of human temporality pointed to "a deeper experience of temporal disruption beyond the physiological and social aspects of desynchronization, one that involves the contraction or closing up of existence itself" (p. 18). For Heidegger, "human existence is time," and thus when our temporal unity is disrupted the future itself closes as "a horizon of possibilities" (p. 18f.). For Aho, when our sense of time is broken it disturbs our understanding of the world and ourselves. He emphasizes the importance of understanding as one of the crucial factors in Heidegger's account: "In this view, I exist or understand who I am only in terms of the meanings that I project for myself," and "in severe cases of structural collapse, when understanding is wholly compromised, the very possibility of being a self is lost" ( $\mathrm{p}$. 20). Ranging from Heidegger's early to late works, while incorporating more recent studies of phenomenological psychopathologies, Aho builds a convincing case for the importance of Heidegger's account and its constitutive elements. By tracking when and how our basic care structure builds or collapses, we achieve a more fully contextualized sense of our suffering and ways to overcome it.

In the rest of Part One Aho shows how Heidegger's approach can be applied to various kinds of mental suffering: depression, anxiety and ontological death. Although many psychiatrists recognize the prevalence of depression in our time, there is considerable debate about its "medical legitimacy" (p. 23). What is missing in this debate, however, is "a critical engagement with the experience of depression itself, with people who actually live with depression" (p. 23). For Aho, what emerges most prominently from people's accounts of depression is a sense of paralysis, the inability to do what they might have done before. What was once the experience of easy functioning becomes an ongoing struggle. Though Heidegger never explicitly described depression as a mood, his analysis of boredom can provide insight into how someone who is depressed responds to the world. For Heidegger, while we may often experience boredom, occasionally we enter a state of 'deep' or 'profound boredom': "In this boredom... nothing appeals to us anymore, everything has as much or as little value as everything else" (p. 27f.). Aho characterizes this as a state of "affective flatness" in which a kind of unreality may occur: "the perception that one's own body is lifeless and unreal" (p. 28f.). In severe cases depression can 
lead to "the global deadening of affective meaning" (p. 31). A phenomenological approach to such a person would put aside scientific and moral judgments and allow the person's first-person account to frame their treatment. The aim is to encourage a compassionate, empathetic response from the therapist.

After depression, Aho applies a Heideggerian approach to anxiety: "In depression... this disruption generally results in sluggishness, a slowing down or retardation of bodily tempos, whereas anxiety is generally experienced in terms of restlessness, speeding up, or acceleration" (p. 39). The person afflicted with anxiety experiences the overwhelming sense of too much information incorporated too quickly. The spatiotemporal, self-organizing unity of the person breaks apart "as the mind jumps from one thought to another, resulting in speech patterns that are sped up, disorganized, and incoherent" (p. 40). Both depression and anxiety reveal how much "the orienting rhythms of our embodiment do not take place in isolation; they are fundamentally relational and social, already bound up in the wider rhythms of an intercorporeal world" (p. 41). As depression closes off our belief in what we are capable of achieving, anxiety reduces our sense of possibilities by suggesting a world without meaning. As a result, with anxiety " the world collapses into itself; (it) has the character of completely lacking significance"" (Heidegger 1978: p. 186; Aho, p. 43). But Aho argues further that the focus on physical and behavioral problems is not sufficient to allow the sufferer of either depression or anxiety to create a new narrative for themselves "in the face of world collapse" (p. 45). With the potential loss of meaning from chronic anxiety the patient needs to imagine themselves anew, not by clinging to a static identity, but rather by acknowledging the instability and malleability of the self as the basis for new possibilities.

The first part concludes with one of Heidegger's most well-known arguments: his account of death. For Aho, Heidegger's sense of "dying" does not refer to the end of physiological functioning, but rather to the loss of the ability to understand the world and oneself. It is a kind of "ontological death" (p. 50), in which the selfcreating, self-interpreting activity of the human being comes to an end. The end of such activity means that our past, present and future potentially lose their meaning and we die to ourselves even while we are physically alive. At the same time, however, if we can anticipate our death with resoluteness, we can find "an opportunity for personal growth and transformation" by confronting our own impermanence and actively creating meaning in our lives. We needn't resign ourselves to a meaningless death, but rather choose to live more authentically with "an attitude of receptivity and openness" to the contingencies of our own existence (p. 56). Aho's reading of Heidegger's resoluteness in the face of death is genuinely helpful, since "resoluteness not only prepares us for the inevitable movement toward old age, disease and death; it can also prepare us for the many 'little deaths' of world collapse" in everyday life (p. 59). Viewed this way, the idea of resoluteness loses both its grim sense of resignation and the implication of a Stormtrooper-like enthusiasm for death. It offers a useful basis for self-care. Aho's book aims to address not only suffering and its many forms, but also to suggest alternative ways of healing based on opening new narrative possibilities for oneself.

In the second part of the book, on "Hermeneutic Psychiatry," Aho describes how a more hermeneutic approach could transform U.S. psychiatry. Hermeneutics, like 
phenomenology, would complicate the medicalized assumptions in biopsychiatry by insisting on the importance of personal, social and historical contexts. Aho works especially with Hans-Georg Gadamer's application of hermeneutics to health issues from the 1996 book, The enigma of health (Gadamer 1996). After he studied with Heidegger in the 1920s, Gadamer pursued a more fully hermeneutic line of thought and developed a rich framework for contextualizing mental health.

For Gadamer, "the enigma of health... is its own concealment or 'hiddenness'... it is an embodied, rhythmic equilibrium that remains "constantly hidden from us"" (1996: p. 112; Aho, p. 71). But when we experience mental illness any sense of equilibrium is disturbed. The familiar, comforting rhythms of our everyday lives become "unintelligible and strange" (p. 71). A more hermeneutic approach to psychiatry would combine the emphasis from natural science with a more human-centered approach so that the patient's first-person narrative could inform their treatment.

The second part of the book deals with the medicalization of three major issues in the U.S.: shyness, stress and rage. In these chapters Aho interweaves his discussion of hermeneutic psychiatry with phenomenology, existentialism, social history and cultural critique. His overarching argument is that the contextualization of the patient would be a better starting point for treatment, as against a one-dimensional biomedical approach.

For much of the American public, Aho asserts, there is the expectation of the self "as a gregarious and assertive extrovert," which privileges the value of extroversion against introversion, reflection and sensitivity (p. 78). As a consequence of privileging extroversion, shyness is pathologized and characterized as a medical condition. Aho wants to show instead that all kinds of social phobia may more likely be the reflection of someone who has trouble coping with the demands of their lives. $\mathrm{He}$ shows, in fact, that the emphasis on extraverted self-assertion had already emerged 174 years ago: "In 1846, Kierkegaard introduced a scathing indictment of the present age, describing the modern self as a gregarious socializer, obsessed with gossip and constantly on the lookout for novelty and distraction" (p. 77). At this point in his account Aho incorporates social and economic history in his narrative about the rise of the "Extrovert Ideal": "In today's neoliberal economy, we are forced into being self-sufficient and self-creating, as we careen from one career, relationship, and geographical location to another" (p. 85f.). Through the establishment of "compulsory extroversion" (p. 86), shyness becomes questionable to the extent that psychiatry produces a kind of selfhood committed to self-assertion, which actually exacerbates anxiety. By now, however, a problem with Aho's narrative arises that would have benefitted from more explicit consideration: how is the notion of a "context" to be understood? Does the "context" of contemporary American life extend all the way to mid-nineteenth century Denmark? If so, it may seem overly elastic. Aho's transdisciplinary interventions into biomedical psychiatry are entirely salutary, but the ubiquity of the notion of context in his narrative calls for a more specific definition.

Perhaps, as he puts it, Aho is more interested in discussing "the psychopathologies of modernity" (p. 102). From a discussion of the medicalization of shyness he turns to other syndromes that are medically difficult to explain. Many of these are marked by complaints of exhaustion, chronic pain, weakness and dizziness. Yet these, too, may rather be responses to the sociohistorical conditions of our time: 
"The kind of chronic insecurity associated with neoliberal capitalism has fundamentally transformed our lives, exacerbating feelings of exhaustion and stress" (p. 101). Aho gives a history of the diagnosis of neurasthenia, which arose in the late nineteenth century and spread from the U.S. to Europe until it disappeared after World War I. Sufferers from neurasthenia shared many of the same symptoms as people who complain, more recently, of chronic fatigue syndrome and fibromyalgia. His point is that diagnoses, too, are subject to historical shifts in understanding the self, mental health and illness. Though they may not be identifiable as specifically physical disorders, "somatic syndromes" nevertheless play crucial roles in the self-understanding of the sufferer (p. 97). It is quite possible, in other words, for someone's somatic issues to become a fundamental part of their identity. In Aho's view: "Hermeneutic psychiatry always begins from the standpoint... that we exist only in the meanings that we create for ourselves" (p. 102). Accordingly therapists need to take more seriously the narratives of their patients and to situate them more empathetically if they want to find more effective treatments.

Ultimately Aho addresses the problem of rage in contemporary American life. According to recent polls, most Americans are outraged about something. In fact the $D S M$ includes a section on "intermittent explosive disorder" (p. 105), which leads to "the medicalization of rage" that can primarily be treated with mood stabilizers. For Aho, we need to approach the widespread anger in U.S. culture hermeneutically, by asking how a person construes meaning in their lives. What is most important to them, and why? At this point Aho brings in Dostoevsky to contextualize rage. He points to "the underground man" from Dostoevsky's Notes from the Underground (1864), Raskolnikov in Crime and Punishment (1866) and Ivan Karamazov from The Brothers Karamazov (1880), to show how "the confusion and rage embodied in these characters" offer "a powerful critique of modernity, its uprootedness from the authority of tradition, and its conception of the self as atomistic and masterful" (p. 109). Again, as with the notion of "context," Aho's argument would be sharpened by a definition of "modernity." How, more precisely, does contemporary American life relate to the nineteenth century in Denmark, Russia, or even the U.S.?

In any event Dostoevsky's writings had a major influence on Heidegger, who also criticized the "groundlessness" (p. 110) of modern life. Aho's point is that American culture suffers from the very groundless, isolated yet assertive and autonomous self that Heidegger and Dostoevsky attack: "the idea of authenticity embodied in the voluntaristic subject appears to have a stranglehold on American identity" (p. 111). To support his position Aho mentions the work of Christopher Lasch on narcissism and Carl Cederstróm on selfishness, individualism and self-actualization. Following these more recent criticisms, Aho argues, American rage is not strictly a biomedical condition, but rather the outcome of the social and historical conditions in which Americans live. Yet he does not recommend the problematic solution offered by Dostoevsky and Heidegger: to return to a mythic past in search of a more indigenous identity. He recommends rather "the great stories of our tradition," which "often radiate conceptions of vulnerability, belongingness, and dependency that invariably clash with the modern values of individualism" (p. 117). In contrast to the mythic tales of a primordial, unified and happy community, Aho recommends narratives that point toward a more intersubjective and relational self and society. 
In the "Afterword" to Contexts, he provides his own first-person narrative in order to situate his work: "the ideas laid out in this book are very personal to me, as I have struggled with depression and anxiety for most of my adult life" (p. 119). In fact it was "teaching and writing about existentialism and phenomenology, especially the work of Heidegger," that helped him to make sense of his experience (p. 119). But then, in December 2018, he suffered a major heart attack and this was "nothing less than world shattering" (p. 122). With this illness he experienced the collapse of space, time, relationships, and meaning that he describes in his book: "I felt as if the future and the past were closing in on me, as if I were trapped in a meaningless present" (p. 124f.). In addition, the treatment he received from medical specialists overwhelmed him with jargon and technology: "The overall impact of this objectification was a feeling of profound helplessness, that I was no longer a participant in my own existence" (p. 126). The turning point came when he accepted his own vulnerability and came to realize that he was "fundamentally defenseless and dependent on others" (p. 130). He came to accept his own need for recognition and validation by others: "For me, without others listening to and caring about my situation, there would be no healing and, consequently, no way of projecting a meaningful path forward" (p. 129). The book ends on an affirmative note that transcends the biomedical approach: "Insofar as our suffering is not just treated with medical technology but heard, acknowledged, and affirmed by others, there is still a way forward; there is still joy in being alive" (p. 130).

Kevin Aho's Contexts of Suffering goes beyond a merely academic work of scholarship. It is a convincing study of Heidegger, to be sure, but also a very personal study of illness in general, and gives a profound response to the over-emphasis on biomedical psychiatry. There are a few formal issues with the book, from the editing to the title, which could be snappier in order to interest a broader audience. Nevertheless, Aho successfully brings together several disciplines-philosophy, psychiatry, social history and cultural critique-to deliver an important statement on the treatment of mental health. Especially in the time of COVID-19 and the growing wave of mental troubles that accompany the pandemic, this book should be read widely for its insightful recommendations as to how people could better be treated under world-shattering conditions.

\section{References}

American Psychiatric Association (APA). 1952-2013. Diagnostic and statistical manual of mental disorders (DSM I-V). Washington: D.C. American Psychiatric Association.

Cederstroom, C. (2018). The happiness fantasy. Cambridge: Polity.

Dostoevsky, F. 1957. (1880). The Brothers Karamazov. (C. Garnett, Trans.). New York: New American Library.

Dostoevsky, F. 1968. (1866). Crime and punishment. (S. Monas, Trans.). New York: New American Library.

Dostoevsky, F. 2009. (1864). Notes from the underground. (C. Garnett, Trans.). Indianapolis: Hackett

Fuchs, T. (2005). Implicit and explicit temporality. Philosophy, Psychiatry and Pathology, 12(3), 195-198. 
Gadamer, H.-G. (1996). The enigma of health. (J. Gaiger \& N. Walker, Trans.). Stanford: Stanford University Press.

Heidegger, M. 1978. (1927). Being and time (BT). (J. Macquarrie \& E. Robinson, Trans.). New York: Harper and Row.

Heidegger, M. 1979. (1936-1937). The will to power as art. In Nietzsche, vol. I. (D. F. Krell, Trans.). New York: Harper and Row.

Heidegger, M. 1992. (1924). The concept of time (CT). (W. McNeill, Trans.). Oxford: Blackwell.

Heidegger, M. 1993. (1947). Letter on humanism. In M. Heidegger, Basic writings (BW) (pp. 213-265), (F. Capuzzi \& J. G. Gray, Trans.). New York: Harper Collins.

Heidegger, M. 2001. (1959-1971). Zollikon seminars: Protocols-Conversations-letters (ZS 1). (F. Mayr \& R. Askey, Trans.). Evanston: Northwestern University Press.

Heidegger, M. 2014-2020. (1931-1957). Schwarze Hefte (Black Notebooks). Ed. P. Trawny. Frankfurt am Main: Vittorio Klostermann.

Kierkegaard, S. (1973). A Kierkegaard anthology. Princeton: Princeton University Press.

Lasch, C. (1978). The culture of narcissism. American life in an age of diminishing expectations. New York: W.W. Norton.

Stanghellini, G., Broome, M., Fernandez, A. V., Fusar-Poli, P., Raballo, A., \& Rosfort, R. (Eds.). (2019). The Oxford handbook of phenomenological psychopathology. Oxford: Oxford University Press.

Publisher's Note Springer Nature remains neutral with regard to jurisdictional claims in published maps and institutional affiliations. 